
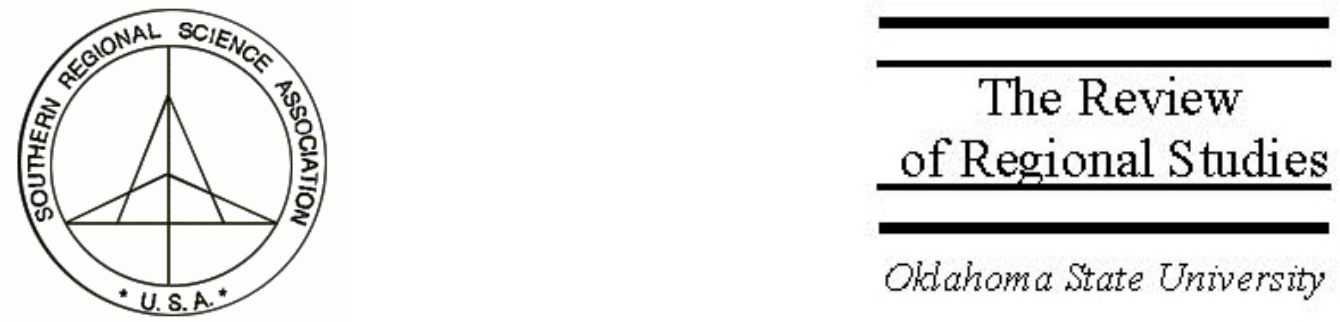

\title{
Regional Productivity Differentials in Three New Member Countries: What Can We Learn from the 1986 Enlargement to the South?
}

\author{
Sandy Dall'erba \\ REAL, University of Illinois at Urbana-Champaign, 607 S. Mathews \#220, Urbana IL \\ 61801-3671, e-mail: dallerba@uiuc.edu
}

Yiannis Kamarianakis

Department of Economics, University of Crete, and Regional Analysis Division, Institute of Applied and Computational Mathematics, Foundation for Research and Technology, P.O. Box 1527, 71110 Heraklion, Greece, e-mail: kamarian@iacm.forth.gr

\section{Julie Le Gallo}

IERSO (IFReDE-GRES), Université Montesquieu-Bordeaux IV, Avenue Léon Duguit, 33608 Pessac Cedex, France, e-mail: legallo@u-bordeaux4.fr

\section{Maria Plotnikova}

Center for Development Research, University of Bonn, Germany, e-mail: plotniko@illinoisalumni.org

\begin{abstract}
The recent enlargement of the European Union (EU) will lead to unprecedented reforms of regional policies. We examine the regional distribution of gross value added, employment, and productivity for the Polish, Hungarian, and Czech regions, and compare them to the EU-15 average for the 1990-2000 period. We study their per capita incomes relative to the EU average and how these gaps are related to differences in productivity per worker. Finally, we use Esteban's (2000) shift-share analysis to explore the extent to which regional productivity gaps are due to differences in industrial mix as opposed to region-specific factors. The results are compared to figures for the Spanish and Portuguese regions a decade before their entrance to the EU.
\end{abstract}

Keywords: Labor productivity; Transition countries; Regional disparities; Shift-share analysis

JEL classification: $J 2 ; R 12 ; R 58$

We worked on this paper while students or visitors at the Regional Economics Applications Laboratory, University of Illinois at Urbana-Champaign. Previous versions were presented at the $50^{\text {th }}$ Annual North American Meetings of the RSAI (Philadelphia, Nov. 2003), the $18^{\text {th }}$ Conference of the PRSO (Acapulco, Mexico, July 2003), and at the REAL seminar series. We thank the participants for their valuable comments. We also acknowledge helpful suggestions from Ronald L. Moomaw and two anonymous referees. 


\section{INTRODUCTION}

The unraveling of post-transition scenarios in the countries of Central and Eastern Europe presents a challenge for regional economic analysis. This transformation has created a hitherto unprecedented turn of economic events. Central planning mechanisms have been replaced by market mechanisms, and at the same time domestic production bases have become linked to wider international markets. This interplay of internal economic transformation and integration into a wider European economy raises important questions about the effects of the transition process on regions as well as future spatial patterns of economic development. Indeed, while the economic gap that separates the original EU-15 members and the new members has been widely assessed in the Commission's reports (European Commission 2001, 2003) and other studies (see for instance, Podkaminer and Havlik 2004), disparities within the new members have been explored much less. ${ }^{1}$ Thus, we aim to study the extent to which Polish, Czech, and Hungarian regional economies differ from the EU average.

The European Union has experienced enlargement with new members having a much lower level of development than the members existing at that time. The 1986 addition of Spain and Portugal increased regional imbalances over the territory (their per capita GDP was, respectively, 51 percent and 28 percent of the one of the EU-10 that year) and has led, as a consequence, to increased regional assistance to the South. Therefore, it is of interest to compare internal disparities of the Eastern countries with the EU average with those experienced by Spain and Portugal a decade before their membership. Using these two Southern countries as a benchmark allows us to assess, to some extent, the efforts necessary to sustain the catching-up of the new members and the nature of policy intervention. $^{2}$ The three new Eastern members have benefited from pre-membership regional assistance programs since 1998, but several questions on the implementation of regional policies remain open: the criteria for assistance eligibility after 2007 have not been voted on yet, and the European budget for the 2007-2013 programming period is still under discussion. Therefore, it is important to study the extent and the origin of regional imbalances within these countries.

In this article, rather than using the usual approach that focuses on regional disparities in income (see for instance, Barro and Sala-i-Martin 1995), ${ }^{3}$ we analyze the extent to which these disparities are due to each component of per capita income, namely aggregate productivity per worker, share of worker over total labor force, and share of the

\footnotetext{
${ }^{1}$ Some exceptions are, among others, Petrakos (2000), Iara and Traistaru (2003), Nemes-Nagy (2000).

${ }^{2}$ In the case of the Iberian countries, Martin (1999) and Dall'erba and Hewings (2003) conclude that regional funds have contributed to a catching-up to the EU average at the national level, but have increased regional disparities within the assisted countries. This is due to the important weight of transportation infrastructures in total investments, which reinforce the agglomeration process.

${ }^{3}$ In the case of transition economies, convergence analyses are mostly performed at the country level (see for example, Campos 2001; Kočenda 2001).
} 
labor force in total population. Regional inequalities in income depend on factors such as capital funding, technology, infrastructure, and human capital. These variables, however, are not always available on a comparable basis at the regional level; consequently, focus is often shifted to labor productivity as a proxy for them (Esteban 2000; Cuadrado-Roura, Mancha-Navarro, and Garrido-Yserte 2000; Cuadrado-Roura 2001). Consistent with this practice, our paper explores the origins of interregional differences in productivity per worker using shift-share analysis.

While shift-share analysis does not imply causality, it is a useful technique for the analysis of transition economies where there is no well-established theory. A descriptive analysis like shift-share is informative; the results can suggest explanations and contribute to building of a theory of the transition process. Moreover, many studies emphasize the regional and sectoral changes that accompany transition (in the case of employment growth differentials, see Boeri and Scarpetta 1996; Traistaru and Wolff 2002). This is related to the emerging body of work on regional performance following the transition, i.e., detecting the losing versus winning regions (Kratke 1999; Nemes-Nagy 2000; Petrakos 2000). The decomposition technique can then be used to trace effects of policy changes where there is a strong sector-region link. For example, in the case of new EU entrants, the EU antidumping policy will be lifted against specific sectors following EU entry (mainly chemical and steel sectors in Poland, Hungary, the Czech Republic, and Slovakia) (Faucompret, Konings, and Vandenbussche 1999). Kennedy (1997) shows that economic reforms in Poland have already been reflected in different patterns of development according to the sector where they were implemented. He distinguishes a group of sectors where restructuring appears to have worked very well from a second group (mostly composed of large, state-owned enterprises) where little change occurred. These sectors are geographically concentrated. The advantage of the shift-share approach rests in its ability to decompose the regional and sectoral components of changes in employment or productivity that follow policy reforms.

Given data availability, analysis is performed on the regions of Poland, Hungary, and the Czech Republic for the period of 1990-2000. In this article, inequalities are related to the difference from the European average because most regional policy funds are allocated according to criteria based on this average. In other words, we use the average of the EU-15 members when the three Eastern countries are considered, whereas we use the average of the 10 former EU members when the prior entry of Spain and Portugal is examined. In each case, the designated baseline does not include the newcomers' characteristics, providing a better understanding of the development gap.

The paper proceeds as follows. Section 2 displays the main features of regional distribution of Gross Value Added (GVA), employment, and productivity growth, compared to the EU average. Section 3 measures the extent to which differentials in regional per capita income can be attributed to aggregate productivity per worker, share of workers in the labor force, and labor force per inhabitants, each expressed as a difference from the EU average. Section 4 relies on the shift-share decomposition introduced by Esteban (2000) where regional productivity growth is modeled as the sum of three components: 
structural, differential, and allocative. We then assess the role played by each of these elements in regional differences in productivity per worker.

\section{EXPLORATORY ANALYSIS FOR PER CAPITA GROSS VALUE ADDED, EMPLOYMENT, AND PRODUCTIVITY}

The most important regional policy instruments take the European average as the reference point for deciding where to allocate development funds. For example, the Objective 1 Structural Funds are allocated to regions with per capita GDP below 75 percent of the European average; the Cohesion Fund, in contrast, is allocated to countries having per capita GDP below 90 percent of the European average. It is therefore important to analyze the evolution of per capita Gross Value Added (GVA), employment, and productivity for the new Eastern members of the EU - both in terms of levels and growth rates and examine where they lie with respect to the EU average. At this exploratory stage of our analysis, we evaluate the evolution of the gap in terms of productivity, employment, and GVA between each region in Poland (16 regions), Hungary (7 regions), the Czech Republic (8 regions), and the EU average ${ }^{4}$ over 1990-2000. The names of these regions are displayed in Table 1.

\section{TABLE 1}

Regions' Code and Name

\begin{tabular}{llllll}
\hline Code & Name & Code & Name & Code & Name \\
\hline & SPAIN & & PORTUGAL & CZ05 & Severovychod \\
ES11 & Galicia & PT11 & Norte & CZ06 & Jihovychod \\
ES12 & Asturias & PT12 & Centro & CZ07 & Stredni Morava \\
ES13 & Cantabria & PT13 & Lisboa e V.do Tejo & CZ08 & Ostrava \\
ES21 & Pais Vasco & PT14 & Alentejo & & POLAND \\
ES22 & Navarra & PT15 & Algarve & PL01 & Dolnoslaskie \\
ES23 & Rioja & PT2 & Acores & PL02 & Kujawsko-Pomorskie \\
ES24 & Aragon & PT3 & Madeira & PL03 & Lubelskie \\
ES3 & Madrid & & HUNGARY & PL04 & Lubuskie \\
ES41 & Castilla-Leon & HU01 & Kozep-Magyarorszag & PL05 & Lodzkie \\
ES42 & Castilla-la Mancha & HU02 & Kozep-Dunantul & PL06 & Malopolskie \\
ES43 & Extremadura & HU03 & Nyugat-Dunantul & PL07 & Mazowieckie \\
ES51 & Cataluna & HU04 & Del-Dunantul & PL08 & Opolskie \\
ES52 & Com. Valenciana & HU05 & Eszak-Magyarorszag & PL09 & Podkarpackie \\
ES53 & Baleares & HU06 & Eszak-Alfold & PL0A & Podlaskie \\
ES61 & Andalucia & HU07 & Del-Alfold & PL0B & Pomorskie \\
ES62 & Murcia & & CZECH REPUBLIC & PL0C & Slaskie \\
ES63 & Ceuta y Melilla & CZ01 & Praha & PL0D & Swietokrzyskie \\
ES7 & Canarias & CZ02 & Strední Cechy & PL0E & Warminsko-Mazurskie \\
& & CZ03 & Jihozapad & PL0F & Wielkopolskie \\
& & CZ04 & Severozapad & PL0G Zachodniopomorskie \\
\hline
\end{tabular}

\footnotetext{
${ }^{4}$ For that purpose, we use the European average of the 15 members of the $1990-2000$ period as the benchmark.
} 
For comparative purposes, we also examine the regions of Spain (18 regions) and Portugal ( 7 regions) and their disparities relative to the EU-10 average for a period preceding their accession (1977-1985). The data are part of the regional database of Cambridge Econometrics (2001). ${ }^{5}$

First, we study the evolution of GVA per capita, productivity, and employment per capita compared to the European average in order to detect phenomena of convergence or divergence towards this European average.

Figures 1 and 2 display the gap that separates the per capita GVA of each region $i$ under study from the European average for the three transition countries and for Spain and Portugal. It can be noted as $(g v a / p o p)_{i} /(g v a / p o p)_{E U}$. It appears that the Polish regions are the best performing in terms of per capita GVA within the sample of transition countries: they have experienced some kind of convergence toward the EU average since they are all characterized by an upward trend. However, this catching up is very unequal between regions, and even the richest of them have to cover a distance almost equal to the one the poorest Spanish ones had to cover 20 years ago. Moreover, the poorest regions of the Eastern countries of our study were more than twice as far from the EU average during 1990-2000 compared to the poorest Portuguese ones during 1977-1985. Polish regions display the largest growth rates; they tend to catch up to the EU levels faster than the Hungarian regions, which have only a slight upward trend, and the Czech regions, which have a downward trend. The latter therefore experience a slight divergence, as did some Portuguese regions.

Second, in contrast with the Czech regions, employment per population levels for the Polish and Hungarian regions ${ }^{6}$ were below the EU-15 average level from 1990 to $2000{ }^{7}$ The difference in the employment rates between Poland and Hungary versus the Czech Republic is representative of the particular restructuring paths that these countries have taken.

The legacy of command-and-control economies has been the inefficient use of labor, which may result in over-employment (Jackman 1994; Dries and Swinnen 2002).

\footnotetext{
${ }^{5}$ Some modifications were necessary before performing the analysis. In the case of Poland, the data on regional employment depict a downward shift for the year 1998 due to a redefinition of regional boundaries within the country that year. It has been corrected using an exponential smoothing algorithm. Data on regional population depicted a much greater level over 1990-1997 than for the 1998-2000 period. Since the REGIO database (created by Eurostat) confirms the data over 1998-2000, we decided to adjust the levels over 1990-1997 to those of the last three years, keeping the same annual growth rates. Finally, the Hungarian regional GVA displays a decline in 1994 as well, but we decided not to correct them since we could not find any evidence that it was due to a data problem.

${ }^{6}$ The same was true for the Spanish and Portuguese regions from 1977 to 1985; in fact, the gap in their case was significantly larger.

${ }^{7}$ These figures are not displayed due to space constraints. They are available from the authors upon request.
} 
FIGURE 1

Ratio of Per Capita GVA of Each of the Polish (top), Hungarian (middle), and Czech (bottom) Regions to the EU Average Over 1990-2000
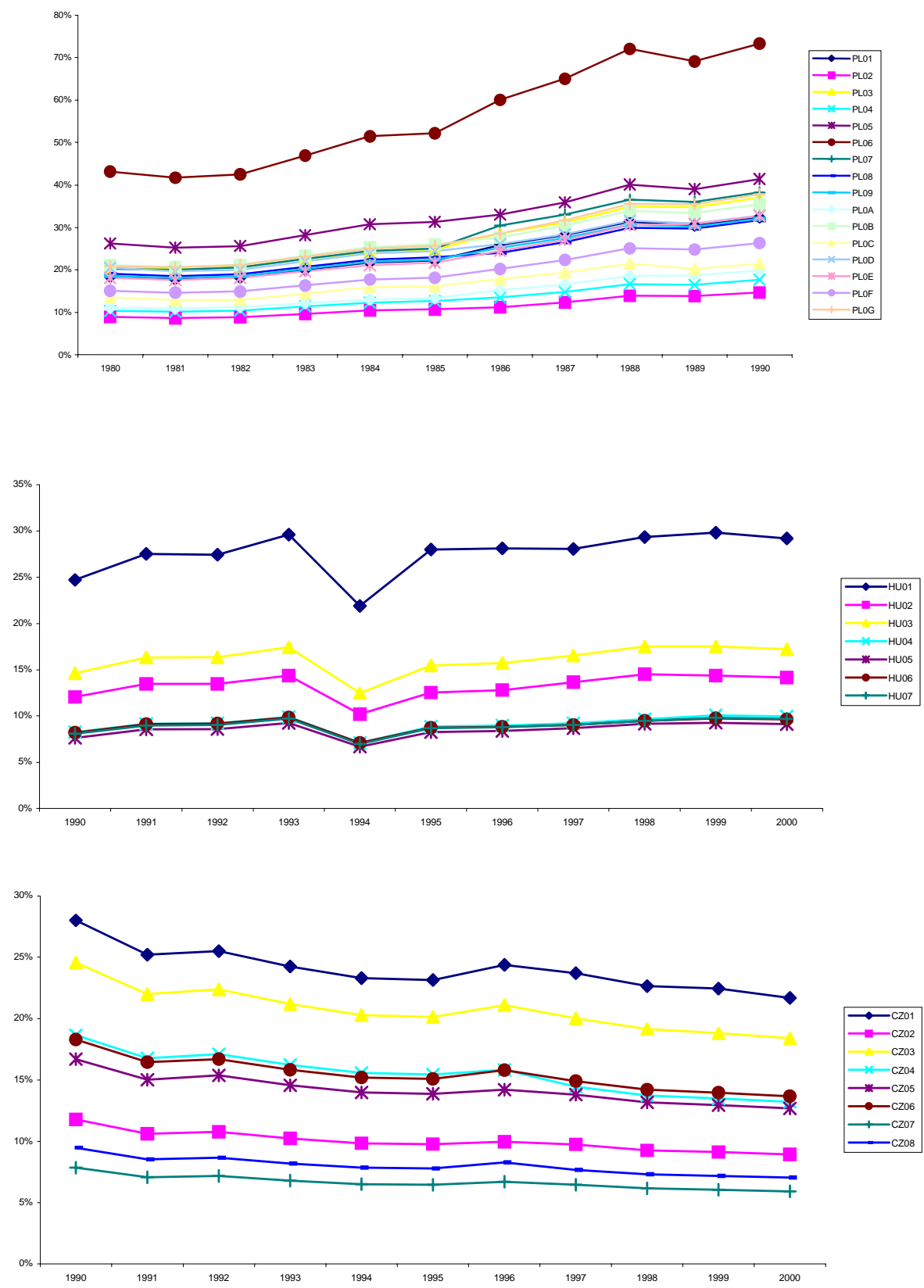

Source: Cambridge Econometrics (2001). See Table 1 for the region's codes and names. 
FIGURE 2

Ratio of Per Capita GVA of Each of the Spanish (top) and Portuguese (bottom) Regions to the EU Average Over 1977-1985
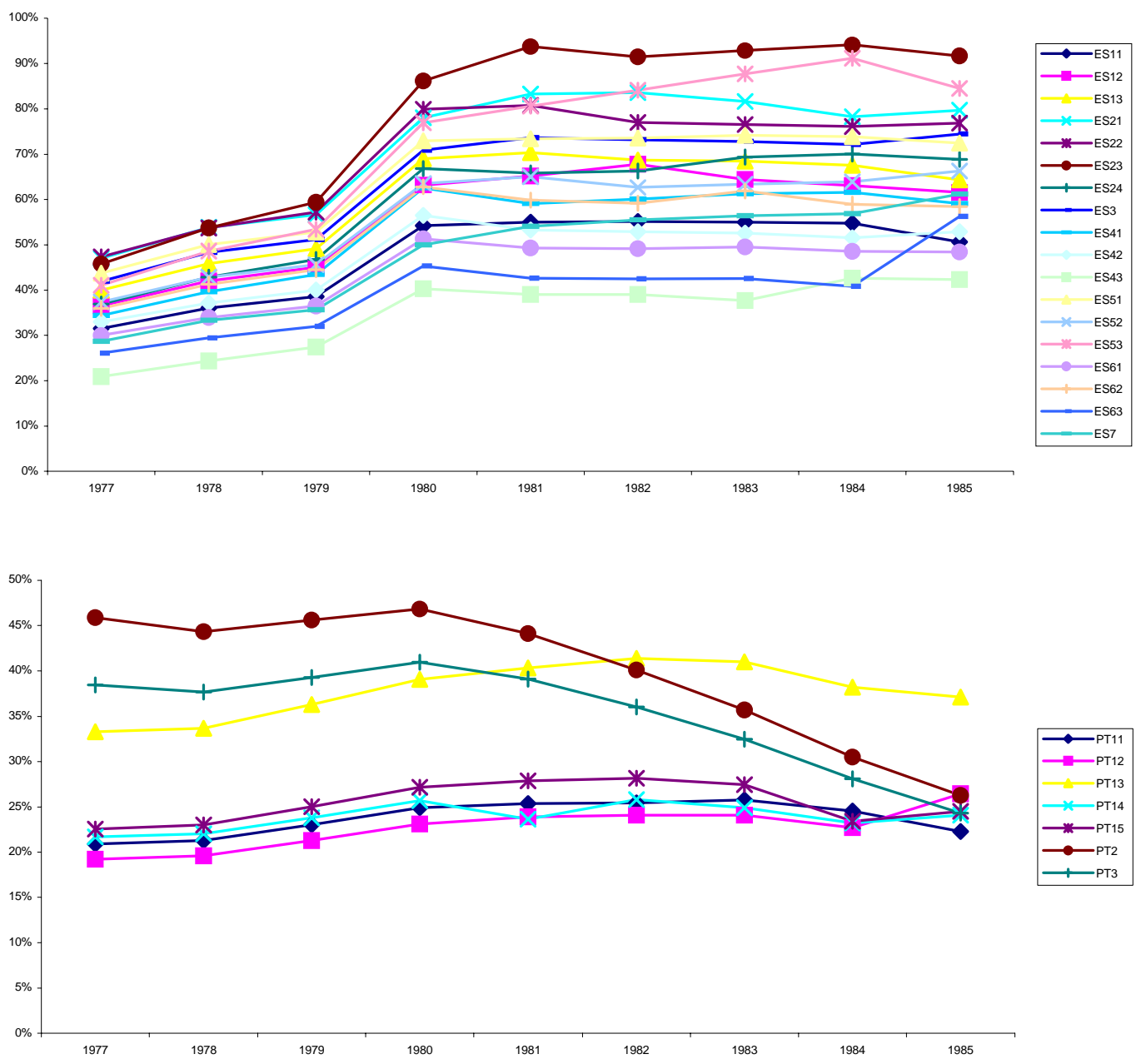

Source: Cambridge Econometrics (2001). See Table 1 for the region's codes and names.

According to Warzynski (2003), high unemployment rates in the case of Poland and Hungary are evidence of painstaking restructuring as their economies change gears. On the contrary, Sorm and Terrell (2000) show that the low unemployment in the Czech Republic during most of the 1990s was due to greater shifts in the structure of sectoral employment compared to the other transition economies.

Third, regional productivities for the Czech Republic tended to diverge from the EU average as time evolved in the 1990-2000 period, whereas the Polish and Hungarian 
regions tended to catch up. For the Polish regions, we note (slightly) increasing regional disparities and point out the leading position of Malopolskie (where Krakow is located), which is by far the best performing region of the Eastern countries dataset in terms of average productivity.

The regional trends in per capita GVA for the Spanish and Portuguese regions are similar to those for the Czech, Polish, and Hungarian regions, although the latter regions had much larger disparities. There was an increasing trend in Spanish regions' productivities during 1977-1985 and most of them approached the EU average, while at the same time regional disparities within Spain were increasing. This is in contrast with the Portuguese regions, where diminishing regional inequalities through a negative trend for the most productive regions were observed.

Consider now the growth rates associated with the three variables: GVA per capita, productivity, and employment. In order to analyze them, we use the Cuadrado-Roura, Mancha-Navarro, and Garrido-Yserte (2000) methodology that establishes a typology of the regional performances according to the difference between the regional growth rates and the EU average. In this respect, Figure 3 displays the differentials in GVA growth of each region, together with differentials in employment and productivity growth for 19902000. First, the regional growth rate is positive or negative depending on its position relative to the solid line. Second, this regional growth rate is below or above the European average depending on its position relative to the dashed line.

Figure 3 shows that regions corresponding to the same country are clustered together. However, several differences are worth mentioning. Following the regional typologies suggested by Cuadrado-Roura, Mancha-Navarro, and Garrido-Yserte (2000), Polish and Hungarian regions belong to the category IIb, relative restructuring. Thus, they are characterized by larger productivity and GVA growth but smaller employment growth ${ }^{8}$ compared to the EU-15 average. In this case, productivity gains have been achieved mainly at the expense of a decrease in employment. The Polish regions are better situated relative to the Hungarian regions since their employment growth is much closer to the EU-15 average. Except for Prague, the Czech regions belong to category III, economic decline. Their productivity, GVA, and employment growth are below the EU-15 average.

Employment growth in Prague, however, is above the EU-15, placing it in category IVA, conservative restructuring. Similarly, Kozep-Magyarorszag (where Budapest is located) displays higher employment growth than the rest of the Hungarian regions. According to Petrakos (2000), employment growth was always higher in capitals during the transition process; Boeri and Scarpetta (1996) also note that the labor market conditions in Prague were exceptional, with up to 10 vacancies per job seeker in 1994.

\footnotetext{
${ }^{8}$ These regions in fact display negative employment growth.
} 
FIGURE 3

Regional Typologies for Poland, Hungary, and the Czech Republic Over 1990-2000

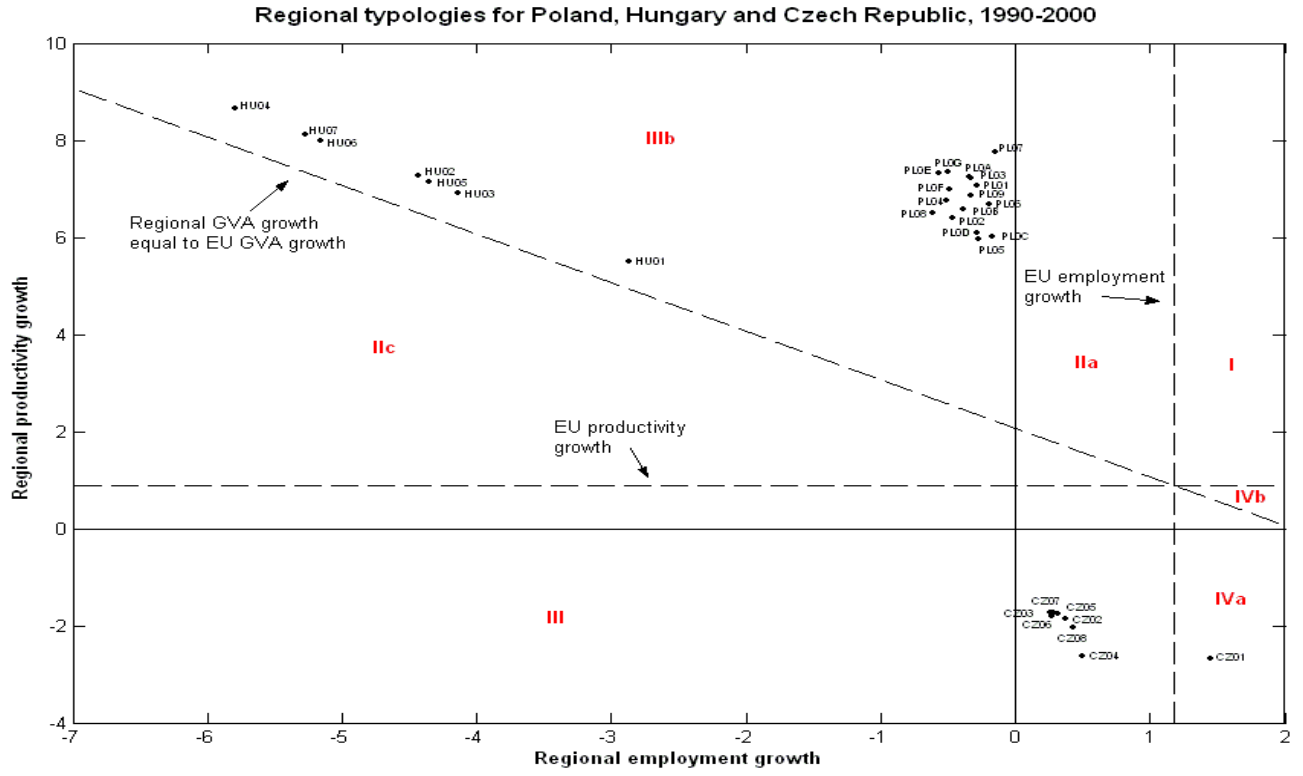

Source: Cambridge Econometrics (2001). See Table 1 for the region's codes and names.

Figure 4 uses the same approach to contrast Spanish and Portuguese regions to the EU-10 average. According to the data, there is increased regional heterogeneity because regional characteristics within the same country differ more compared to the previously examined Eastern countries. Two Spanish regions (Ceuta y Melilla and Baleares) display larger productivity, employment, and GVA growth than the EU-10 average. However, the results for these two regions should be considered carefully because they are remote and very small regions not representative of Spanish regions in general. In fact, the rest of the Spanish regions and four Portuguese regions (Norte, Centro, Lisboã, and Alentejo) belong to the category IIb, as do the Polish and Hungarian regions. Thus, their greater productivity and GVA growth relative to the EU-10 average is at the expense of smaller employment growth. The three remaining Portuguese regions are Algarve, the Azores, and Madeira. Algarve belongs to category IIa, dynamic restructuring, with productivity and GVA growth greater than the EU-10 average but positive employment growth, although less than the average. The Azores belong to category III, vicious circle, having smaller productivity, GVA, and employment growth than the EU-10 average. Finally, Madeira is in the category IVa, conservative restructuring; relative to the EU-10, it displays larger employment growth but smaller GVA and productivity growth. 
FIGURE 4

Regional Typologies for Spain and Portugal Over 1977-1985.

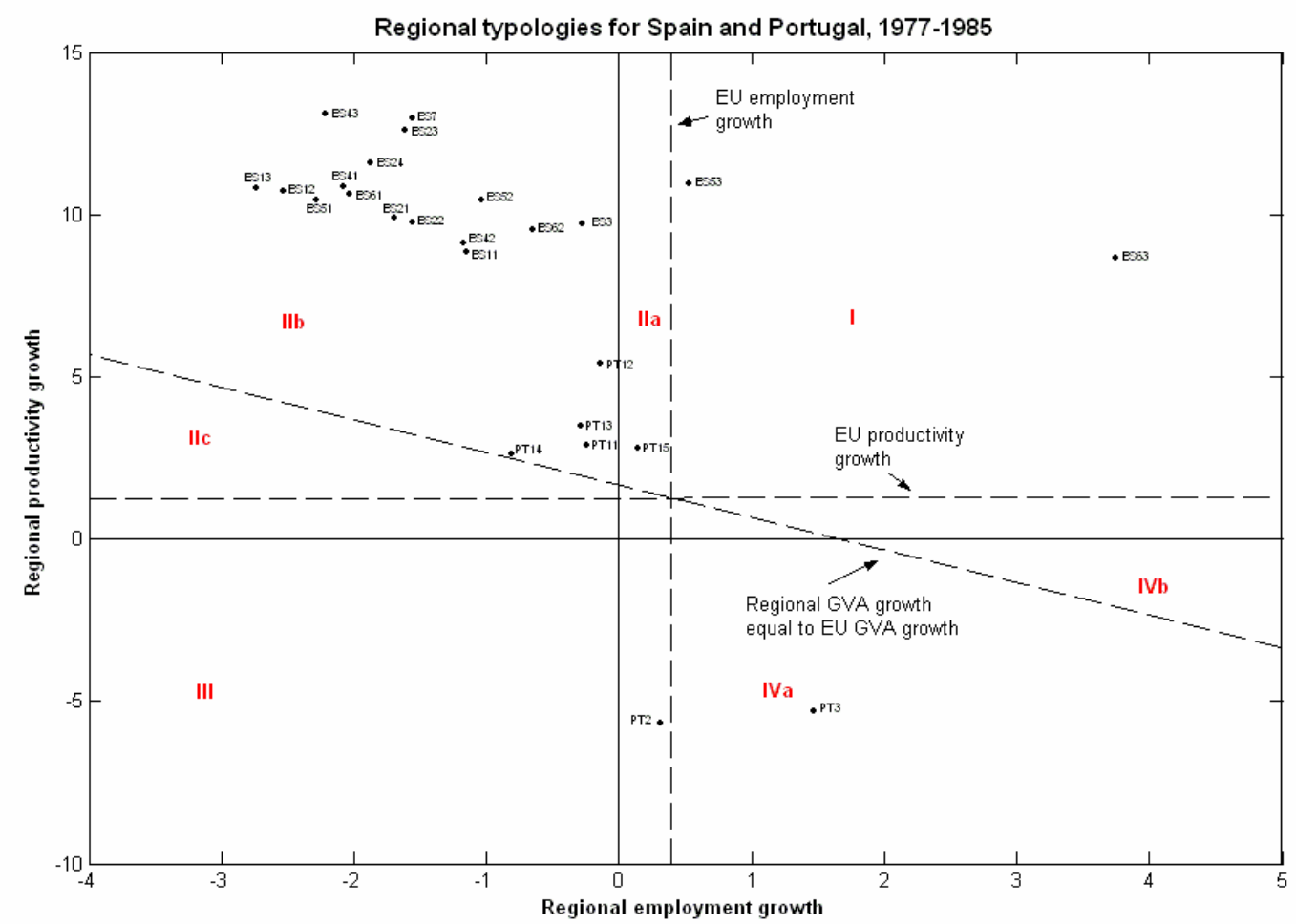

Source: Cambridge Econometrics (2001). See Table 1 for the region's codes and names.

This exploratory part of the analysis suggests that differences in Polish and Hungarian employment and productivity growth relative to the EU-15 average are close to the ones observed for the Spanish and Portuguese regions a decade before they joined EU-10. The case of the Czech Republic seems more alarming, since its regions (except Prague) are characterized by negative differential productivity, employment, and GVA growth. In the next section, we decompose regional income inequalities to bring more insights into the role of productivity differentials in explaining income differentials to the European average.

\section{DECOMPOSITION OF REGIONAL INCOME INEQUALITIES}

At this point, we express the GVA per population for each region $i$ as the product of three terms: aggregate productivity per worker, share of employment in the labor force, and share of the labor force in total population. Thus, we get the following equation: 


$$
\left(\frac{g v a}{p o p}\right)_{i}=\left(\frac{g v a}{w}\right)_{i} *\left(\frac{w}{l}\right)_{i} *\left(\frac{l}{p o p}\right)_{i}
$$

where $g v a$ is GVA, pop is the population, $w$ is the number of workers, and $l$ is the labor force. Therefore, the element on the left-hand side is region $i$ 's per capita GVA; on the right-hand side, the first element is region $i$ 's productivity per worker, the second element is the share of employees in the labor force, and the last one is the labor force per inhabitants in region $i$. In logarithmic form, expression (1) becomes:

$$
\log \left(\frac{g v a}{p o p}\right)_{i}=\log \left(\frac{g v a}{w}\right)_{i}+\log \left(\frac{w}{l}\right)_{i}+\log \left(\frac{l}{p o p}\right)_{i}
$$

Similarly, for the European average, this expression is:

$$
\log \left(\frac{g v a}{p o p}\right)_{E U}=\log \left(\frac{g v a}{w}\right)_{E U}+\log \left(\frac{w}{l}\right)_{E U}+\log \left(\frac{l}{p o p}\right)_{E U} .
$$

Subtracting (3) from (2) we get:

$$
\begin{aligned}
& \log \left(\frac{g v a}{p o p}\right)_{i}-\log \left(\frac{g v a}{p o p}\right)_{E U}=\log \left(\frac{g v a}{w}\right)_{i}-\log \left(\frac{g v a}{w}\right)_{E U}+\log \left(\frac{w}{l}\right)_{i}-\log \left(\frac{w}{l}\right)_{E U} \\
& +\log \left(\frac{l}{p o p}\right)_{i}-\log \left(\frac{l}{p o p}\right)_{E U} .
\end{aligned}
$$

One way of measuring the role of each component in explaining the total difference in GVA of each region to the EU average is to compute the relative weight of the variance of each component in the overall observed variance, together with terms collecting the covariances:

$$
\begin{aligned}
\operatorname{var}\left(\frac{g v a^{*}}{p o p}\right)= & \operatorname{var}\left(\frac{g v a^{*}}{w}\right)+\operatorname{var}\left(\frac{w^{*}}{l}\right)+\operatorname{var}\left(\frac{l^{*}}{p o p}\right) \\
& +2 \operatorname{cov}\left(\frac{g v a^{*}}{w}, \frac{w^{*}}{l}\right)+2 \operatorname{cov}\left(\frac{g v a^{*}}{w}, \frac{l^{*}}{p o p}\right)+2 \operatorname{cov}\left(\frac{w^{*}}{l}, \frac{l^{*}}{p o p}\right)
\end{aligned}
$$

Each element in brackets corresponds to the respective logarithmic difference (between the region and the EU average) expressed in (4), the last elements being terms collecting the covariance between the three previous variables. Boeri and Scarpetta (1996) used a similar variance decomposition when they studied six European transition economies. In their analysis, the variance of regional employment rates of change was 
decomposed into a main component explained by structural changes and a residual related to regional effects.

The results for three different years are displayed in Table 2. Most of the variance of per capita GVA for the Polish regions is attributable to productivity per worker differentials to the EU average; it represents an average of 1.05 times the variance of per capita GVA differentials. The results for the Czech and Hungarian regions clearly support the idea that per capita GVA variances come from differentials in the share of the labor force in total population (around 0.8 in both countries, whereas productivity differentials count for less than 0.23 in total per capita GVA variance). In contrast, in the 1977-1985 period, most of the variance of per capita GVA differentials for the Spanish regions is attributed to the share of employment in the labor force. The income decomposition for the Portuguese regions revealed some similarities to the Polish case, with most of the variance of per capita GVA attributed to productivity per worker differentials.

As far as the evolution of variances over time ${ }^{9}$ is concerned, the results differ from one country to another as well. In Poland, the variance of regional productivity per worker differentials increases by 2 percent. It decreases by 84 percent within Portugal, indicating a convergence of productivity per worker levels among its regions. Within the Czech Republic and Hungary, the variance of the share of the labor force in total population differentials increases by 6 and 34 percent, respectively, indicating increasing regional differences within these countries. Note, however, that this increase is steadier in Hungary.

Since only Poland and Portugal present similarities in the decomposition of their regional per capita GVA, we switch our focus to a decomposition of productivity differentials using the shift-share approach. This methodology allows analyzing the extent to which inequalities in aggregate labor productivity can be attributed to region-specific or to sector-specific factors.

\section{SHIFT-SHARE DECOMPOSITION OF PRODUCTIVITY DIFFERENTIALS}

In this section, we further decompose regional labor productivities. For that purpose, our analysis is based on the shift-share approach as it is depicted in Esteban $(1972,2000)$. The shift-share decomposition was first used by Dunn (1960) as a forecasting technique for growth in regional employment. More recently, it was applied by Esteban (1972, 2000), who analyzed productivity changes among the European regions. Regarding the countries studied in this article, Traistaru and Wolff (2002) performed it on the regions of Romania, Bulgaria, and Hungary to study regional employment growth while GarciaMila and Marimon (1999) applied it to the regional growth rate of employment and productivity in Spain. They conclude that regional differences in employment growth are not particularly responsive to the inherited employment structure of the various regions; they are driven almost entirely by region-specific effects.

\footnotetext{
${ }^{9}$ Complete results available from the authors upon request.
} 
TABLE 2

Share of Total Variance by Component

\begin{tabular}{|c|c|c|c|c|c|c|c|}
\hline & & $\begin{array}{c}(1) \\
\text { Labor productivity }\end{array}$ & $\begin{array}{l}\text { (2) } \\
\text { Employees in } \\
\text { the labor force }\end{array}$ & $\begin{array}{c}(3) \\
\text { Labor force per } \\
\text { inhabitant }\end{array}$ & $\begin{array}{c}\text { Covariance (1) } \\
\text { and (2) }\end{array}$ & $\begin{array}{l}\text { Covariance } \\
\text { (1) and (3) }\end{array}$ & $\begin{array}{c}\text { Covariance (2) } \\
\text { and (3) } \\
\end{array}$ \\
\hline \multirow{3}{*}{ Poland } & 1990 & 1.064 & 0.002 & 0.214 & -0.030 & -0.289 & 0.039 \\
\hline & 1995 & 1.050 & 0.005 & 0.182 & -0.048 & -0.246 & 0.057 \\
\hline & 2000 & 1.032 & 0.007 & 0.146 & -0.044 & -0.204 & 0.064 \\
\hline \multirow{3}{*}{ Hungary } & 1990 & 0.175 & 0.000 & 0.586 & 0.002 & 0.216 & 0.020 \\
\hline & 1995 & 0.073 & 0.007 & 0.693 & 0.011 & 0.074 & 0.141 \\
\hline & 2000 & 0.084 & 0.004 & 0.807 & 0.001 & -0.014 & 0.118 \\
\hline \multirow{3}{*}{ Czech Republic } & 1990 & 0.224 & 0.001 & 0.777 & -0.002 & -0.033 & 0.033 \\
\hline & 1995 & 0.113 & 0.002 & 0.825 & -0.022 & 0.039 & 0.043 \\
\hline & 2000 & 0.164 & 0.000 & 0.812 & -0.007 & 0.020 & 0.011 \\
\hline \multirow{3}{*}{ Spain } & 1977 & 0.721 & 1.819 & 0.482 & -0.601 & 0.120 & -1.542 \\
\hline & 1981 & 0.549 & 1.052 & 0.224 & -0.164 & 0.020 & -0.681 \\
\hline & 1985 & 0.665 & 0.445 & 0.172 & -0.106 & 0.004 & -0.180 \\
\hline \multirow{3}{*}{ Portugal } & 1977 & 1.671 & 0.854 & 0.758 & -0.603 & -0.189 & -1.491 \\
\hline & 1981 & 1.721 & 0.944 & 0.782 & -0.431 & -0.466 & -1.550 \\
\hline & 1985 & 1.159 & 1.186 & 1.295 & 0.328 & -0.763 & -2.206 \\
\hline
\end{tabular}


While our analysis is based in Esteban's (2000) approach, it contains some modifications. Esteban analyzes the productivity differentials of European regions and the benchmark is the EU average. In other words, each region is part of the benchmark it is compared with; in this article, no region belongs to the benchmark. ${ }^{10}$ Moreover, in contrast with Esteban (2000) and following Traistaru and Wolff (2002), the shift-share decomposition is performed for a number of consecutive years, which is more relevant for assessing the dynamics of inequality in aggregate productivity per worker.

The methodology can be briefly formulated as follows: let $p_{i}^{j}$ be sector $j$ 's ${ }^{11}$ employment share in region $i$ so that $\sum_{j} p_{i}^{j}=1$ for all regions $i^{12}$. We denote by $p_{E U}^{j}$ sector $j$ 's employment share at the European level (EU-15 for the Eastern countries case, EU-10 for the Spanish and Portuguese cases). We also have $\sum_{j} p_{E U}^{j}=1$. Similarly, we denote by $x_{i}^{j}$ the productivity per worker in sector $j$ and region $i, x_{E U}^{j}$ at the European level, respectively.

Therefore, the following equalities hold:

$$
\begin{aligned}
& x_{i}=\sum_{j} p_{i}^{j} x_{i}^{j} \\
& x_{E U}=\sum_{j} p_{E U}^{j} x_{E U}^{j} .
\end{aligned}
$$

The regional differential in productivity per worker between region $i$ and the European average is therefore: $x_{i}-x_{E U}$. Esteban (2000) shows that the regional differential in productivity per worker can be attributed to three possible causes. The first one is due to the specialization of a region in the more productive sectors, which would result in regional aggregate productivity above the mean, even if the productivity of each single sector is the same at any location. It may result from local advantages that have been growing with history. The second cause comes from each region's sector-by-sector productivity differential to the average, assuming that the sectoral composition of the regional industry is the same as the one at the European level. It may come from previous investments in technology, human capital, and public infrastructures. The third cause of differential in productivity per worker is a combination of both previous ones. Formally, Esteban shows that the gap between regional and European average productivities can be decomposed into three components and formulated as follows:

\footnotetext{
${ }^{10}$ The benchmark in our case consists of the 15 EU members and the 10 EU members for 19902000 and 1977-1985, respectively.

${ }^{11}$ Five economic sectors are concerned in our application: agriculture, construction, total energy and manufacturing, nonmarket services, and market services.

${ }^{12}$ Index $i$ ranges from 1 to 31 for the dataset of the Eastern countries and from 1 to 25 for the dataset of the Spanish and Portuguese regions. Index $j$ ranges from 1 to 5 for all of them.
} 


$$
y=x_{i}-x_{E U}=\mu_{i}+\pi_{i}+\alpha_{i}
$$

where:

- $\mu_{i}$ is the industry-mix component of region $i$ measuring the differential in productivity per worker between region $i$ and the EU average due to the specific sectoral composition of its industry. It is defined as $\mu_{i}=\sum_{j}\left(p_{i}^{j}-p_{E U}^{j}\right) x_{E U}^{j}$ and takes positive values if the region is specialized (i.e. $p_{i}^{j}>p_{E U}^{j}$ ) in sectors with high productivity compared to the European level or de-specialized (i.e. $p_{i}^{j}<p_{E U}^{j}$ ) in sectors of low productivity. It reaches its maximum if the region is specialized in the most productive sector.

- $\pi_{i}$ is the productivity differential component focusing on productivity differentials due to region $i$ 's sector-by-sector productivity differential to the EU average, assuming that the region's industry mix coincides with the European one. It is defined as $\pi_{i}=\sum_{j} p_{E U}^{j}\left(x_{i}^{j}-x_{E U}^{j}\right)$ and takes on positive values if the region has sectoral productivities above the European average.

- $\quad \alpha_{i}$ is the allocative component; it is a combination of the two previous components. It is defined as $\alpha_{i}=\sum_{j}\left(p_{i}^{j}-p_{E U}^{j}\right)\left(x_{i}^{j}-x_{E U}^{j}\right)$ and is positive (negative) if the region is specialized, relative to the European average, in sectors whose productivity is above (below) the European average. $\alpha_{i}$ is at its maximum if the region is completely specialized in the sector with the largest productivity differential with respect to the European average. The allocative component can also be viewed as measuring the covariance between the two previous components.

We analyzed the evolution over time of the three components using the data on the five sectors cited above. First, the industry mix component evolves steadily with no trend for the Polish and Czech regions, whereas there is a clear increasing trend for the Hungarian regions. The industry mix component of the Czech regions is strictly positive during the 1990-2000 period. Most of the Polish regions have negative industry mix values, whereas after 1994 practically all the Hungarian regions display positive industry mix values. The Spanish regions behave similarly to the Polish ones (no trend and mostly negative industry mix values), whereas the Portuguese ones display negative values with no trending behavior. For these last three countries, the results may be due to the importance of the agricultural sector in the economy.

Second, the productivity differential component leads to similar observations as the ones that came out for the aggregate productivity levels. Regional disparities appear to be significantly less important in the Eastern countries than in Spain and Portugal. On the other hand, their difference with the European average is much greater than it was some years ago for the Spanish and Portuguese regions. However, two regions behave in 
a different way: Malopolskie in Poland and Prague in the Czech Republic are unlike the other Eastern European regions and are close to the EU average.

Third, the allocative component is characterized by decreasing dynamics (from positive values towards zero) for Hungary and Poland and steady dynamics close to zero for the Czech regions. Prague is an outlier again since its values are significantly less important than the other Czech regions' values. The allocative component for the Portuguese regions increases from small negative values towards zero. On the other hand, the values of the Spanish regions oscillate around zero.

To measure the role played by each component in explaining regional differences in aggregate productivity per worker, we perform a variance decomposition as in Section 3.

$$
\operatorname{var}(y)=\operatorname{var}\left(\mu_{i}\right)+\operatorname{var}\left(\pi_{i}\right)+\operatorname{var}\left(\alpha_{i}\right)+2 \operatorname{cov}\left(\mu_{i}, \pi_{i}\right)+2 \operatorname{cov}\left(\mu_{i}, \alpha_{i}\right)+2 \operatorname{cov}\left(\pi_{i}, \alpha_{i}\right) .
$$

The results for three different years are displayed in Table 3.

Table 3 indicates that for Poland, Spain, and Portugal most of the variance of the differential in productivity per worker between each region and the European average can be attributable to the productivity differential component. In other words, the main factors determining interregional per worker productivity differences between the regions of these countries and the EU average are region-specific factors that have a homogeneous effect on productivity across sectors. In contrast, the industry mix component is most important in Hungary while the allocative component is largest in the Czech Republic in 1990 and 1995, but smaller than the productivity differential component in 2000.

These last results do not indicate the extent or the exact nature of policies that should be supported in the least developed regions. However, the experience in the Iberian regions indicates that interregional transportation infrastructures, which have been the main sector financed by regional policies, have not been an efficient instrument to reduce regional disparities (Vickerman 1995; Venables and Gasiorek 1999). Indeed, they have reinforced the agglomeration process and led to increasing regional disparities within Spain and Portugal over the last two decades (Dall'erba and Hewings 2003). According to the most recent proposals of the European Commission (European Commission 2004a, 2004b), it appears that improving accessibility through new transportation infrastructures will still be one of the major priorities for the 2007-2013 programming period.

\section{CONCLUSION}

A reconsideration of the origin of regional imbalances within the transition countries is necessary for two reasons. First, the speed of the reforms implemented involves changes in the distribution of income that must be taken into account for political and equity reasons. Second, it is necessary to reexamine the current regional policy in order to prevent a budget deficit due to the development gap of the new members. This paper 
TABLE 3

Share of Total Variance by Component

\begin{tabular}{|c|c|c|c|c|c|c|c|}
\hline & & $\begin{array}{c}\text { (1) } \\
\text { Industry mix }\end{array}$ & $\begin{array}{c}(2) \\
\text { Productivity } \\
\text { differential }\end{array}$ & $\begin{array}{c}\text { (3) } \\
\text { Allocative }\end{array}$ & $\begin{array}{c}\text { Covariance (1) } \\
\text { and (2) }\end{array}$ & $\begin{array}{l}\text { Covariance } \\
\text { (1) and (3) }\end{array}$ & $\begin{array}{c}\text { Covariance (2) } \\
\text { and (3) }\end{array}$ \\
\hline \multirow{3}{*}{ Poland } & 1990 & 0.955 & 1.038 & 0.493 & 0.098 & -1.303 & -0.282 \\
\hline & 1995 & 0.537 & 1.124 & 0.232 & 0.012 & -0.582 & -0.322 \\
\hline & 2000 & 0.173 & 1.163 & 0.104 & -0.016 & -0.106 & -0.318 \\
\hline \multirow{3}{*}{ Hungary } & 1990 & 14.274 & 0.624 & 10.597 & 1.247 & -24.567 & -1.173 \\
\hline & 1995 & 2.170 & 0.561 & 1.482 & 1.344 & -3.527 & -1.031 \\
\hline & 2000 & 1.579 & 0.463 & -1.053 & 1.575 & -2.512 & -1.158 \\
\hline \multirow{3}{*}{ Czech Republic } & 1990 & 1.338 & 3.027 & 3.563 & 3.764 & -4.294 & -6.398 \\
\hline & 1995 & 9.990 & 33.626 & 65.018 & 35.765 & -50.353 & -93.046 \\
\hline & 2000 & 1.049 & 27.208 & 26.968 & 9.411 & -9.688 & -53.949 \\
\hline \multirow{3}{*}{ Spain } & 1977 & 1.578 & 0.566 & 0.389 & 0.127 & -1.244 & -0.417 \\
\hline & 1981 & 0.399 & 0.457 & 0.066 & -0.131 & 0.177 & 0.030 \\
\hline & 1985 & 0.482 & 0.488 & 0.160 & -0.435 & 0.316 & -0.012 \\
\hline \multirow{3}{*}{ Portugal } & 1977 & 0.358 & 2.636 & 0.501 & -0.364 & 0.089 & -2.220 \\
\hline & 1981 & 0.432 & 2.229 & 0.520 & -0.761 & 0.428 & -1.847 \\
\hline & 1985 & 1.535 & 1.953 & 1.119 & -0.154 & -1.389 & -2.064 \\
\hline
\end{tabular}


meets these expectations by bringing more insights into the differences in per capita GVA between the regions of three candidate countries - namely Hungary, Poland, the Czech Republic - and the European average and by comparing them with those that Spain and Portugal, two of the poorest countries of the EU-15, experienced a decade before their membership.

When the main features of regional distribution of GVA, employment, and productivity growth are displayed, it appears that the characteristics of the Hungarian and Polish regions are similar to the ones of most of the Spanish and Portuguese regions. Compared to the EU average, their greater growth in employment and GVA occurred at the expense of reduced employment. On the contrary, all three variables display a smaller growth (than the EU average) in the Czech regions, representative of their economic decline. Moreover, these results point out the large gap in GVA and productivity levels between all the regions of Poland, Hungary, the Czech Republic and the EU average. This differentiates these candidate countries from the previous entrants, Spain and Portugal, which exhibited smaller gaps with the EU average. Cohesion efforts will thus necessarily be much higher than those implemented for Spain and Portugal. On the other hand, none of the new member displays as much heterogeneity among its own regions as Spain and Portugal used to. This may facilitate the implementation of policies that support development across all their regions. At the same time, we identify differences between the three accession countries. Indeed, Poland seems to be on the trajectory of a slow catching up to the EU average; Hungary would be the intermediate case, and the Czech Republic is trailing behind.

Next, the results of our investigation indicate that per capita GVA gaps can mostly be attributed to the variance of differentials in aggregate productivity per worker in the Polish and Portuguese regions. For Hungary and the Czech Republic, the results support the idea that they mostly come from the variance of differentials in the labor force over total population. The Spanish regions are the only ones to display a variance of employment in the labor force as the most important share of their per capita GVA variance. Therefore the new members present different characteristics of regional per capita GVA than the Iberian countries did before their membership, with the exception of Poland and Portugal. As a consequence, we switch our interest to regional productivity differentials (to the EU average) that we decompose, according to the shift-share methodology developed by Esteban (2000), into three elements: the industry mix (structural component), the region-specific factors (differential component), and the allocative component (a combination of the previous two). When we analyze the respective variance share of each component on total variance, the results show that the productivity differential component explains most of the variance of regional productivity differences to the EU average in Poland, Spain, and Portugal. In Hungary, most of this variance is explained by the industry mix component, while the weight of the allocative component dominates in the Czech Republic, except in 2000. Therefore, our findings do not lend themselves to treating regional disparities in these new member countries in the same way. For instance, Poland might use funds benefiting all the sectors homogenously in its least developed regions, through investment in technology or human capital. On the other hand, the Hungarian regions might call for policies increasing the weight of the most 
productive sectors in the more backward regions. The situation is less clear for the Czech regions, which need to improve both regional and sectoral productivities. The allocation of regional funds over the coming 2007-2013 programming period should therefore be adapted to the situation of each country. This does not mean that regional policies that have been implemented in Spain and Portugal since 1986 should be repeated. Indeed, if most of the variance of their productivity differentials come from the productivity differential component, as in the case of the Polish regions, heavy investments in transportation infrastructures led to firm agglomeration in the rich regions and increased internal disparities. We therefore recommend that the European Commission treat each member's difficulties individually and focus its efforts on the other aspects of regional policies since infrastructures are only one part of the program for balanced regional development.

\section{REFERENCES}

Barro, R.J. and X. Sala-i-Martin, 1995. Economic Growth. McGraw-Hill: Boston.

Boeri, T. and S. Scarpetta, 1996. "Regional Mismatch and the Transition to a Market Economy," Labour Economics 3(3), 233-254.

Campos N.F., 2001. "Will the Future be Better Tomorrow? The Growth Prospects of Transition Economies Revisited," Journal of Comparative Economics 29(4), 663676.

Cuadrado-Roura, J.R., 2001. "Regional Convergence in the European Union: From Hypothesis to the Actual Trends," Annals of Regional Science 35(3), 333-356.

Cuadrado-Roura, J.R. and T. Mancha-Navarro, and R. Garrido-Yserte, 2000. "Regional Productivity Patterns in Europe: An Alternative Approach," Annals of Regional Science 34(3), 365-384.

Dall'erba, S. and G.J.D. Hewings, 2003. "European Regional Development Policies: The Trade-Off between Efficiency-Equity Revisited," REAL Discussion Paper 03-T2, University of Illinois at Urbana-Champaign.

Dries, L. and J.F.M. Swinnen, 2002. "Institutional Reform and Labor Reallocation During Transition: Theory Evidence from Polish Agriculture," World Development 30(3), 457-474.

Dunn, E.S., 1960. "A Statistical and Analytical Technique for Regional Analysis," Papers and Proceedings of the Regional Science Association, 6, 97-112.

Esteban, J., 1972. "A Reinterpretation of Shift-Share Analysis," Regional and Urban Economics 2(3), 249-261. , 2000. "Regional Convergence in Europe and the Industry Mix: A Shift-Share Analysis," Regional Science and Urban Economics 30(3), 353-364.

European Commission, 2001. "Real Convergence in Candidate Countries - Past Performance and Scenarios in the Pre-accession Economic Programmes," Brussels. , 2003. "Economic Forecasts for the Candidate Countries Spring 2003," European Economy Enlargement Papers No. 15, Brussels. , 2004a. "Cohesion Policy: The 2007 Watershed, Legislative Proposals by the European Commission for the Reform of Cohesion Policy (2007-13 Period)," Brussels. , 2004b. "Third Report on Economic and Social Cohesion," Brussels. 
Faucompret, E., J. Konings, and H. Vandenbussche, 1999. "The Integration of Central and Eastern Europe in the European Union: Trade and Labour Market Adjustment," Journal of World Trade 33(6), 121-145.

Garcia-Mila, T. and R. Marimon, 1999. "Regional Integration and Public Investment in Spain," in J. Adams and F. Pigliaru (eds.), Economic Growth and Change: National and Regional Patterns of Convergence and Divergence. Edward Elgar: Cheltenham, U.K.

Iara, A. and I. Traistaru, 2003. "Integration, Regional Specialization and Disparities in EU Accession Countries: Evidence from Hungary," Paper prepared for the Conference on Cohesion Reform in a Larger Union, College of Europe, Brugge, 3-4 April.

Jackman, R., 1994. "Economic Policy and Employment in the Transition Economies of Central and Eastern Europe: What Have We Learned?" International Labor Review 133(3), 327-345.

Kennedy, R.E., 1997. "A Tale of Two Economies: Economic Restructuring in PostSocialist Poland," World Development 25(6), 841-865.

Kočenda, E., 2001. "Macroeconomic Convergence in Transition Countries," Journal of Comparative Economics 29(1), 1-23.

Kratke, S., 1999. "Regional Integration or Fragmentation? The German-Polish Border Region in a New Europe," Regional Studies 33(7), 631-641.

Martin, P., 1999. "Public Policies, Regional Inequalities and Growth," Journal of Public Economics, 73(1), 85-105.

Nemes-Nagy, J., 2000. "The New Regional Structure in Hungary," in G. Petrakos, G. Maier, and G. Gorzelak (eds.), Integration and Transition in Europe: The Economic Geography of Interaction. Routledge Studies in the European Economy: London.

Petrakos, G., 2000. "The Spatial Impact of East-West Integration in Europe," in G. Petrakos, G. Maier, and G. Gorzelak (eds.), Integration and Transition in Europe: The Economic Geography of Interaction. Routledge Studies in the European Economy: London.

Podkaminer, L. and P. Havlik., 2004. "Transition Countries on the Eve of EU Enlargement," Vienna Institute for International Economic Studies, Research Reports, 303 (special issue on the transition economies), February.

Sorm, V. and K. Terrell, 2000. "Sectoral Restructuring and Labor Mobility: A Comparative Look at the Czech Republic," Journal of Comparative Economics, 28(3), 431-455.

Traistaru, I. and G.B. Wolff, 2002. "Regional Specialization and Employment Dynamics in Transition Countries," ZEI Working Paper, no.B18-2002, Bonn: Center for European Integration Studies.

Venables, A. and M. Gasiorek, 1999. "Evaluating Regional Infrastructure: a Computable Equilibrium approach," in Study of the Socio-economic Impact of the Projects Financed by the Cohesion Fund-A Modelling Approach, vol. 2. Luxembourg: Office for Official Publications o the European Communities

Vickerman, R., 1995. "Location, Accessibility and Regional Development: the Appraisal of Trans-European Network," Transport Policy, 2(4), 225-234.

Warzynski, F., 2003. "The Causes and Consequences of Sector-Level Job Flows in Poland," Economics of Transition 11(2), 357-38. 